\title{
Urban flood modelling and climate change: A Melbourne area case study
}

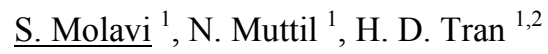 \\ ${ }^{1}$ School of Engineering and Science, Victoria University, PO Box 14428, Melbourne, Vic. 8001, Australia; \\ Email: shahram.molavi@live.vu.edu.au; nitin.muttil@vu.edu.au; dung.tran@vu.edu.au;. ${ }^{2}$ Institute of \\ Sustainability and Innovation, Victoria University, Australia
}

\begin{abstract}
Flooding in urban cities can cause damage to properties, disruption to business and traffic, discomfort to community and in some worse cases human loss. Floods occur due to meteorological, hydrological and human factors, which can be categorized as climate change and urbanization. Each of these factors will have its own effects on urban flooding; however, few studies have been conducted to assess the combined effects of these factors on that. Furthermore, the variability of flooding may increase in future due to climate change as well as increase in urbanization.

We need to assess the risk of flooding to get a proper proactive preparedness. One case study to assess the effects of above mentioned factors in Melbourne area have been selected. Flooding in urban area is considerably sensitive to not only the intensity and duration of extreme events but also to hydrologic and hydraulic attributions of urban areas. Based on this as well as inputs from the council in Melbourne, climate change and urbanization been identified as key factors for increase in urban flooding. Urbanization is further sub-divided into the following three factors:
\end{abstract}

- Increase in imperviousness in the catchment

- Change in storage capacity of the catchment

- Change in conveyance capacity of the catchment.

This paper will present a proposed research study to assess the urban flooding due to the combined effects of the above mentioned four factors (namely climate change as well as the three urbanization related factors). Furthermore, it will present the result of simulating climate changes and downscaling their impacts on urban catchment, which is one of the first steps in implementation of the proposed study. Climate change effect could be studied using Global Climate Models (GCMs). These GCMs have been used to project global climate change in next 100 years based on different development trends and global greenhouse gas emission scenarios. The outputs of GCMs are at low resolutions and cannot be used for any local area directly. In this study, we are using Statistical Downscaling Methodology (SDSM) which is a hybrid of stochastic weather generator and regression-based downscaling methods to generate high resolution climate data.

The results of the research imply variation in both amount and frequency of maximum daily rainfall for current century in compare to the present baseline. The trends of climate regime are toward more dry days and less precipitation. SDSM downscaling is not enough for undertaking the effects of climate change on extreme subdaily (high intensity and low duration) events that are projected to be more frequent due to climate change. A proper disaggregation is essential for generating extreme events.

Keywords: Climate change, Global Climate Models (GCM), Statistical downscaling, Statistical Downscaling Model (SDSM) 


\section{INTRODUCTION}

Since 1975, natural disasters have claimed the lives of more than 2.2 million people world wide. Storms, floods, droughts, heat waves and other weather-related phenomena are responsible for two thirds of the fatalities and economic losses from the natural disasters (UNISDR 2009). Climate change increases disaster risks in two ways. First, climate change will likely increase the frequency and/or severity of weather and climate hazards (IPCC 2007). Second, climate change will simultaneously increase communities' vulnerability to natural hazards due to the combined effects of ecosystem degradation, reduced availability of resources, and changes in peoples' livelihoods (UNISDR 2009). In Australia, flooding causes the most damage of all natural disasters and each year extreme rainfall events due to climate change and variability cause significant damage. As a result of flooding, the damage from the Queensland recent floods could be $1 \%$ of the Gross Domestic Product or more than $\$ 10$ billion and cut the economic growth to fall up to $1 \%$ over 2011 (ABC Finance Report 2011).

Climate change is expected to have a change in intensity and frequency of extreme rainfall events (Mailhot et al., 2010). In urban areas, because of the anthropogenic effects, like transforming the natural drainage to fast collecting facilities and disposal of sediments and solid wastes, the risk of flash flooding have increased. The duration and volume of runoff would be changed by the pattern of underground and overland drainage systems, permeability and the capacity of recharging (Karamouz et al., 2010). Urbanization leads to more impervious areas and therefore the maximum flood discharge will be increased and time of runoff concentration will be decreased.

This project was developed to assess the impacts of climate change and urbanization on urban drainage system at a local scale. In this paper, a brief description of the project is explained and the results of the base stage of downscaling and finally conclusion and completing activities are presented.

\section{CASE STUDY AND METHODOLOGY}

Springvale area in City of Greater Dandenong in eastern part of Melbourne was selected as a case study. This area consists of 17 catchments ranging from 18 to 579 ha. The schematization of the hydraulic parameters of the catchment such as pipes, pits and topography were available in associated GIS files. Since the data is currently not available for calibration of the model, a flowmeter will be installed at the catchment outlet in the near future.

The tasks of the project are shown in Figure 1. A hydrologic/hydraulic model will be used to simulate rainfall-runoff under different climate and land use scenarios. A typical continuous series of precipitation will be used to produce flood sequences.

The frequency analysis will be implemented to compare flood volumes and return periods of present and future scenarios. If the system fails for future scenarios, then the mitigation plans to attenuate the peaks of floods into acceptable levels will be implemented by changing 3 major factors:

- Percent of imperviousness

- Drain conveyance capacity

- Storage capacity in terms of retention and detention

The results of sensitivity and uncertainty assessment will be used to produce a set of thresholds for the 3 major factors to keep the system in serviceable condition with regards to future climate variability.

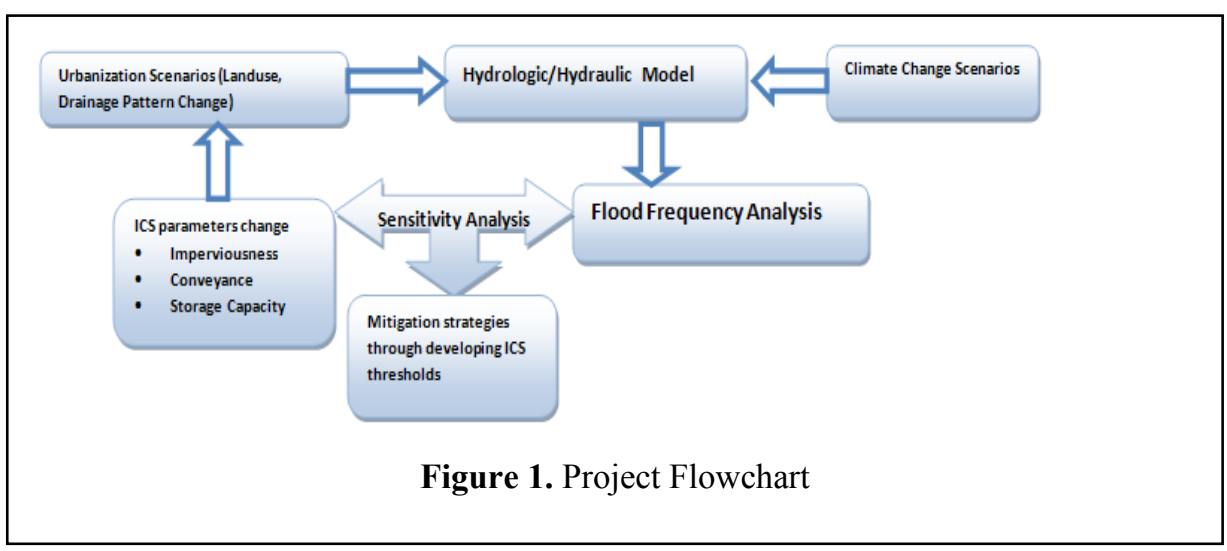




\section{DOWNSCALING PROCEDURES}

\subsection{SDSM methodology}

The creation of future climate change scenarios will be implemented using Global Climate Models (GCMs). GCMs simulate climate using six emission scenarios derived from Special Report on Emission Scenarios (in increasing adverse effects order namely: B1, B2, A1T, A1B, A2, A1FI). SRES represents different future technological and economical development that might influence greenhouse gases (Nakicenovic et al., 2000). The GCMs produce projections of climate change in low spatial and temporal resolutions (i.e. square of hundreds of kilometres and monthly basis) which is considered not suitable for local climate projection. Because of this, GCM outputs need to be downscaled to be applicable into hydrologic and hydraulic models.

So far two sets of techniques have emerged in order to derive high-resolution local weather variables from large scale, low-resolution climate predictors; namely Statistical Downscaling and Dynamic Downscaling. Dynamic Downscaling uses output from global models to produce initial conditions and time-dependant lateral meteorological boundary conditions. These models are mostly complex and computationally expensive (Maerens et al., 2003). In Statistical Downscaling methodologies, regional or local climate information is derived by first determining statistical models which relate large-scale climate variables (or"predictors") to regional and local variables (or"predictands") (Wilby et al., 2004a). Advantage of statistical downscaling methods are their low computational demand but they are highly sensitive to empirical relations between predictors and predictands as well as transfer functions for downscaling (Wilby et al., 1998, Winkler et al., 1999).

Statistical Downscaling Model (SDSM) (Wilby et al., 2002) is a statistical downscaling technique. It is a hybrid of a stochastic weather generator and regression-based downscaling methods. The large-scale circulation patterns and atmospheric moisture variables are used to linearly condition local-scale weather generator parameters (e.g. precipitation occurance and intensity) (Wilby et al., 1999). The software performs five discrete processes: (1) screening of predictors; (2) model calibration; (3) synthesis of observed data; (4) generation of climate change scenarios; (5) diagnostic testing and statistical analysis (Wilby et al., 2002).

Details of SDSM computation can be found in Wilby et al. (2002) and Karamouz et al. (2010) and is briefly explained here. Daily probabilities of none-zero precipitation (a wet-day) $\omega_{i}$ for a given day $i$ were downscaled using the Predictor variables and a lag-1 autocorrelation parameter. The random variable $\omega_{i}$ was modelled using the following regression equation:

$$
\omega_{i}=\alpha_{o}+\alpha \omega_{i-1} \omega_{i-1}+\sum_{j=1}^{n} \alpha_{j} \hat{u}_{i}^{(j)}
$$

$\hat{u}_{l}^{(j)}$ is the normalized amount of predictor $\mathrm{j}$ on day $i$, and $\alpha_{j}$ is estimated regression coefficient. A uniformly distributed random number $r_{i}, 0 \leq r \leq 1$ was used to determine whether precipitation occurs. For a given site and day, a wet-day was returned if $\omega_{i} \leq r_{i}$.

If precipitation is determined to be occurred, the daily precipitation amount is also downscaled from predictor variables.

$$
Z_{i}=\exp \left(\beta_{o}+\sum_{j=1}^{n} \beta_{j} u_{l}^{(j)}+\varepsilon\right)
$$

Where $Z_{i}$ is the wet-day precipitation amount for a given day $i$ and are always non-zero. $\beta_{i}$ is the estimated regression equation for predictor $\mathrm{j}$, and the normally distribution stochastic error term $\mathcal{E}$ (Wilby et al., 1999).

\subsection{Generating time series}

Daily time series rainfall from Moorabbin gauge station (Moorabbin Airport located at longitude, latitude and height of -37.98, 145.10, 12 m respectively) have been extracted from 1/1/1961 to 31/12/1990. 
The following link (www.cics.uvic.ca/scenarios/sdsm/select.cgi) contains predictors prepared to be used in SDSM.

Australia and New Zealand are contained within $10.0-47.5^{\circ} \mathrm{S}$ longitude and $112.5-180.0^{\circ} \mathrm{E}$ latitude. Coordination of Moorabbin station should be applied in the website to extract associated predictor variables. For each coordination, predictor variables that already normalized could be obtained in a zip format. Each file consisted of three specific data namely National Centers for Environmental Prediction (NCEP) for current predictors and GCMs from Hadley Center Coupled Model Version 3 (HadCM3) A2 and B2 emission scenarios for projection. A brief description of each component is found below:

- NCEP_1961-2001: This directory contains 41 years of daily observed predictor data, derived from the NCEP re-analyses, normalized over the complete 1961-1990 period. These data were interpolated to the same grid as $\mathrm{HadCM} 3\left(2.5^{\circ}\right.$ latitude $\mathrm{x} 3.75^{\circ}$ longitude) before the normalization was implemented.

- H3A2a_1961-2099: This directory contains 139 years of daily GCM predictor data, derived from the HadCM3 A2(a) experiment, normalized over the 1961-1990 period.

- H3B2a 1961-2099: This directory contains 139 years of daily GCM predictor data, derived from the HadCM3 B2(a) experiment, normalized over the 1961-1990 period.

Predictor variables explain a physical regional scale climate characteristic that would be used to predict and derive local weather variables (e.g. rainfall and temperature).

Mean sea level pressure (MSLP), $500 \mathrm{hPa}$ geopotential height (P500), $800 \mathrm{hPa}$ geopotential height (P800), near surface specific humidity (SHUM), Near surface relative humidity (RHUM), Relative humidity at 500 hPa height (R500), Relative humidity at $850 \mathrm{hPa}$ height (R850) and Near surface specific humidity (SHUM) were selected as candidate predictors. Screening best explaining predictors is a trial and error procedure. These predictors were selected due to their relation to pressure and humidity and before going further it is necessary to screen the most proper ones for the continuing of the downscaling.

The procedure of implementing downscaling methodology using SDSM can be found in Wilby et al. (2004b). In the first step to screen the most proper predictors, the more correlated predictors-predictand relationship should be identified. In Figure 2 the results of explained variance for each predictor variable in determination of rainfall is shown. The strongest correlation in each month are shown in red and underlined, indicating that the relationship between rainfall as predictand and P500 and P850 and RHUM as predictors are most important. Blanks represent insignificant relationships.

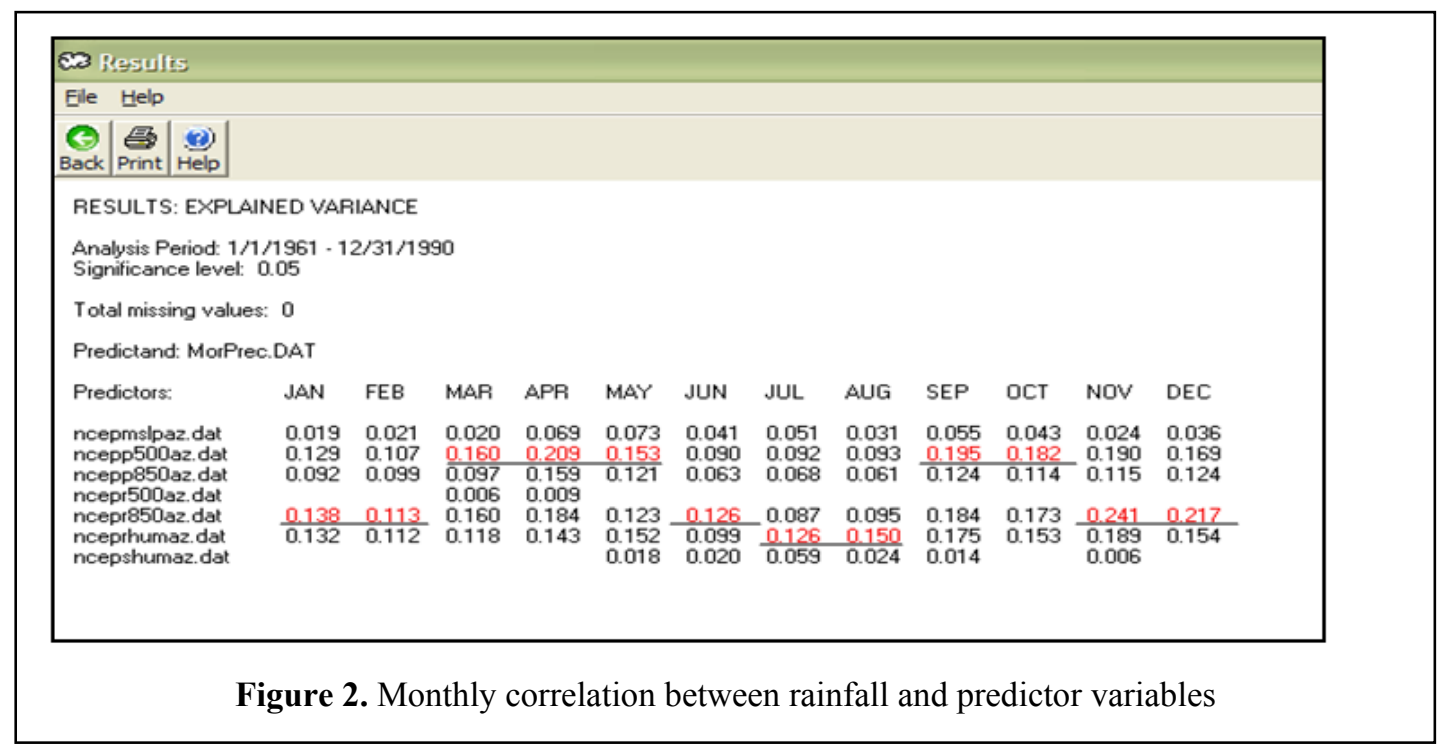

Three candidate variables, namely $500 \mathrm{hPa}$ geopotential height (P500), $800 \mathrm{hPa}$ geopotential height (P800) and Near surface relative humidity (RHUM) were selected as predictor variables for the downscaling procedure. In the second step, SDSM establishes and calibrates the multiple linear regression relation between predictors and predictands. Data within period of 1961-1980 from NCEP for predictor variables and rainfall from Moorabbin gauge station as predictand were fed into the model. The results of the process are the coefficients of the linear regression and are saved in a *.PAR file for further references. 
It is possible to confirm linearity of the model through scatter plots of predictors and predictand. If the scatter plot reveals non linear relationship, a suitable transformation function for predictors or predictand could be used.

The third step is deriving a process to validate the model. Validation of the model could be done by comparing the recorded observed data and synthetic daily rainfall series. The Weather generator operation generates ensembles of synthetic daily weather series given daily observed atmospheric predictor

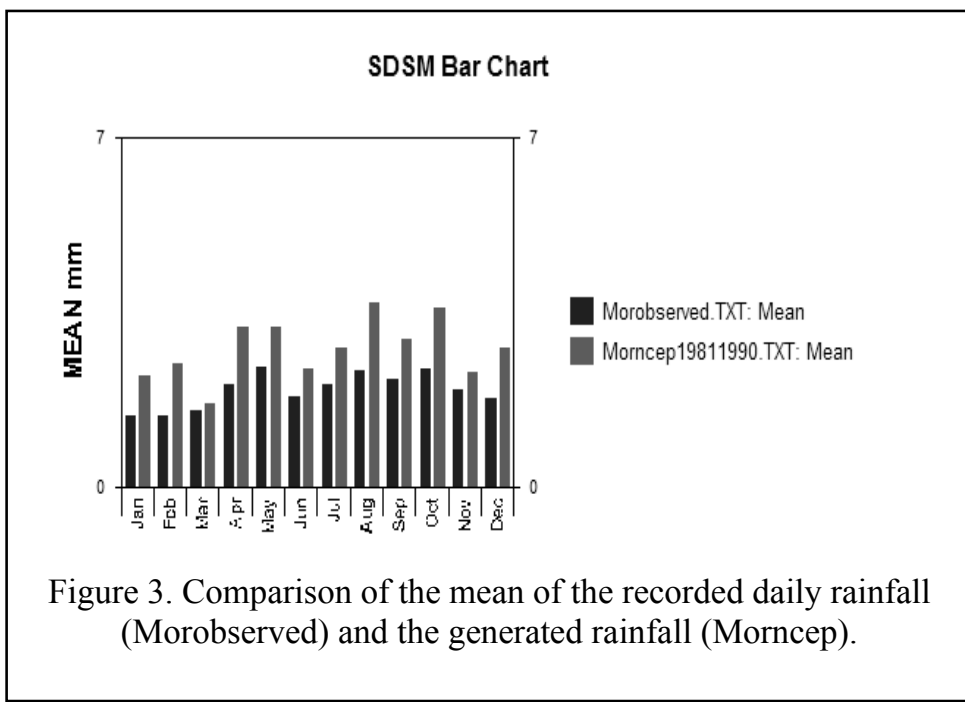
variables. Data within the period 1981-1990 were used for this purpose. SDSM follows a Monte Carlo procedure to reproduce values from a normal distribution with standard deviation equal to the calibration standard error (Wilby et al., 2002).

Figure 3 explains the differences between the mean of the recorded data and the generated daily rainfall through the weather generator within 1981-1990.

In all months model generated greater values in the mean but the pattern is the same. Based on Figure 3, it is possible to assume that regression model generates rainfall conservatively in their mean.

The coefficients of the regression model resulted from calibration procedure would be utilised to project the climate in a horizon of current hundred years using GCMs.

The fourth step is the generation of the climate change scenarios. The model in this step produces ensembles of synthetic daily weather given daily atmospheric predictor variables supplied by a GCM either for current or future climate (Wilby et al., 2002). In this research, two emission scenarios namely A2 and B2 as explained in SDSM Methodology were experimented. The process is the same as validation and the software gives the flexibility to synthesise different number of ensembles for further analysis.

The predictor variables of HadCM3 and the daily observed data were applied to the weather generator. At this stage synthetic rainfall time series for a horizon of 100 years will be projected. In the following the results of the $\mathrm{A} 2$ and $\mathrm{B} 2$ emission scenarios for rainfall has been compared to extract the necessary parameters for the further analysis and investigation of the effects of climate change in the hydrologic models.

\subsection{Delta Factors}

Although daily projection could be beneficial for understanding the pattern of rainfall regime in future but is still too coarse to be applied into a hydrologic or hydraulic model for the assessment of urban flooding. Delta change (DC) method (also called the perturbation or direct change factor approach) is a popular way to implement climate scenario data into hydrologic models (Veijalainn et al., 2010). DC factors are estimated by obtaining the differences of present and future

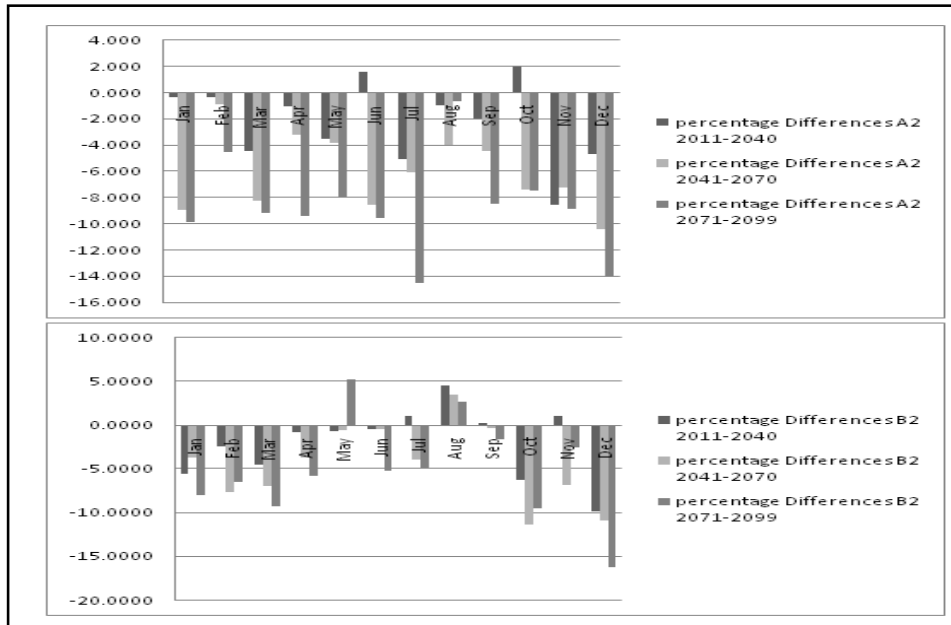

Figure 4. Delta factors as percentage differences to 1961-1990 
climate change model outputs, respectively. Then the factor is applied to observed rainfall and temperature time series for subsequent use (Olesson et al., 2009).

Figure 4 shows percentage differences of specific periods 2011-2040, 2041-2070 and 2071-2099 in proportion to 1961-1990 as the baseline.

Baseline and time series are from projected scenarios using A2 and B2. The results imply that $5 \%$ increase in quantity of precipitation in May and August undertaking B2 emission scenario is expectable. Under A2 we expect to have a decline in average daily precipitation in compare to the present days (1961-1990).

Direct downscaling into subdaily resolution probably could explain the variability of extreme events more properly. Hydraulic models could be checked against rainfall with 5\% increase in compare to the recorded baseline.

\subsection{Frequency analysis}

Frequency analysis helps us to obtain return period of the events. Different generated scenarios using predictors from NCEP and HadCM3 have been used for this purpose. Frequency analysis can show the effects of future greenhouse gases development on the variability of the events quantity. In this research Extreme-Value Type I (Gumbel 1958) distribution fitted to estimate maxima of the synthetic rainfall series. The probability density function for the type I extreme- value distribution is given by Gumbel as follows (Chen 2006):

$$
f(x)=\frac{1}{a} \exp \left\{ \pm \frac{x-b}{a}-\exp \left[ \pm \frac{x-b}{a}\right]\right\},-\infty<x<\infty,-\infty<b<\infty, a>0
$$

Where $a$ and $b$ are scale and location parameters, $b$ is the mode of the distribution and the minus of the \pm used for maximum values. The plus of the \pm is used for minimum values.

The cumulative distribution is shown in Figure 5. The cumulative distributions are most useful in determining the return periods of extreme events like maximum rainfalls.

From Figure 5 (top); decreasing in return periods for daily maximum values from 1961-1990 to 2071-2099 is obvious. Meanwhile there would be a jump from 2011-2040 to 2041-2070 showing temporary increase of maximum daily events. Development according B2 pattern in Figure 5 (down) implies a considerable increase in maximum daily events. No considerable change in return periods from 1961-1990 to 2011-2040 is projected. Like A2 emission scenarios, B2 projects a temporary increase in maximum daily events for period of 2040-2017 and a dramatic decline for period of 2071-2099.

Based on B2 emission scenarios we will project more flash rainfall in 60 years

\section{DISCUSSION AND CONCLUSION}

This paper shows the results of downscaling methodology for the assessment of the impacts of climate change on urban drainage system. The progress should be continued in order to disaggregate the daily rainfall results into subdaily temporal pattern. The results explain variability in rainfall extents during current century but unable to present the flash events and extremes. The summary of conclusion and further actions are as follows:

- Different types of transform functions are available to be used for predictors and predictand variables. Taking these functions into account probably improves the correlation of regression equation. This procedure in

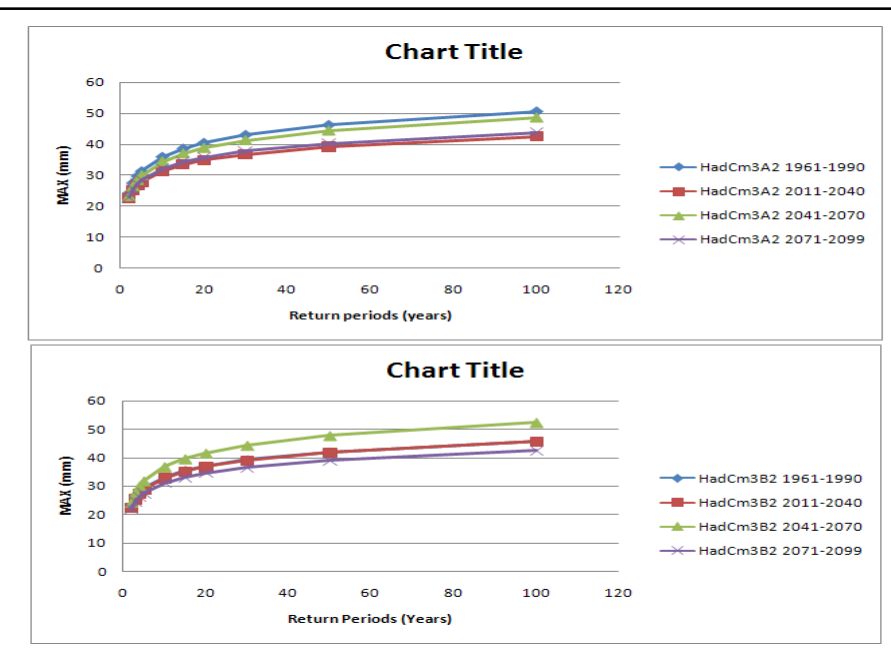

Figure 5. Cumulative distribution of maximum values for HadCM3 A2 (top) and B2 (down) 
SDSM could be done manually;

- Although daily results show increasing maximum rainfall in some specific months in parts of current century, the trend is toward decreasing maximum rainfall. It implies the effects of climate change as having more dry years in future in both development scenarios;

- This methodology is not able to project flash events with high intensities and low duration that would lead to flooding;

- Further work should be done to disaggregate data into subdaily resolution but Delta factors showing difference between present and future daily precipitation could be used as a guide and rough method;

- Any results coming from GCMs are subject to uncertainty. This fact should be taken into account in any assessment using GCMs.

\section{ACKNOWLEDGMENT}

The authors acknowledge the efforts of Mr. Martin Wong from City of Great Dandenong in providing GIS information regarding the selected case study area.

\section{REFERENCES}

ABC Finance News, (2011). Westpac Queensland Flood Report, http://www.abc.net.au/news/stories/2011/01/12/3111114.htm.

Chen, D.A., (2006). Water resources engineering. Second edition. Pearson Education, Inc. USA. 271-333.

Gumbel, E.J., (1958). Statistics of extremes. Columbia University Presss, New York.

Karamouz, M., Hosseinpour, A., Nazif, S., (2010). Improvement of urban drainage system performance under climate change. Journal of Hydrologic Engineering, Posted ahead of print 6 September 2010.

Mailhot, A., Duchesne, S., (2010). Design criteria of urban drainage infrastructures under climate change. Journal of Water Resources Planning and Management 136, 201-208.

Mearns, L. O., Giorgi, F., Whetton, P., Pabon, D., Hulme, M., Lal, M., (2003). Guidelines for use of climate scenarios developed from regional climate model experiments. Technical Report. The IPCC Data Distribution Centre, Norwich, UK, 38 pp.

Nakicenovic, N., Alcamo, J., Davis, G., Vries, B. D., Fenhann, J., Gaffin, S., Gregory, K., Grübler, A., Jung, T. Y., Kram, T., La Rovere, E. L., Michaelis, L., Mori, S., Morita, T., Pepper, W., Pitcher, H., Price, L., Raihi, K., Roehrl, A., Rogner, H., Sankovski, A., Schlesinger, M., Shukla, P., Smith, S., Swart, R., van Rooijen, S., Victor, N., Dadi, Z., (2000). Emissions scenarios, a special Report of Working Group III of the Intergovernmental Panel on Climate Change. Cambridge University Press, Cambridge, UK and New York, USA, $599 \mathrm{pp}$.

Olsson, J., Berggren, K., Olofsson, M., Viklander, M., (2009). Applying climate model precipitation scenarios for urban hydrological assessment: A case study in Kalmar City, Sweden. Atmospheric Research 92, 364-375.

United Nations International Strategy for Disaster Reduction Secretariat (UNISDR), (2009). Global assessment report on disaster risk reduction, http://www.unisdr.org/eng/risk-reduction/climatechange/climate-change.html.

Veijalainen, N., Lotsari, E., Alho, P., Vehviläinen, B., Käyhkö, J., (2010). National scale assessment of climate change impacts on flooding in Finland. Journal of Hydrology 391, 333-350.

Wilby, R. L., Hassan, H., Hanaki, K., (1998). Statistical downscaling of hydrometeorological variables using general circulation model output. Journal of Hydrology 205, 1-19.

Wilby, R. L., Dawson, C. W., Barrow, E. M., (2002). SDSM- a decision support tool for the assessment of regional climate change impacts. Journal of Environmental Modeling and Software 17, 147-159.

Wilby, R.L., Charles, S. P., Zorita, E., Timbal, B., Whetton, P., and Mearns, L. O., (2004a). Guidelines for use of climate scenarios developed from statistical downscaling methods. Supporting Material of the Intergovernmental Panel on Climate Change, Available from the DDC of IPCC TGCIA, 27pp.

Wilby, R.L., Dawson, C. W., (2004b). Using SDSM version 3.1 - a decision support tool for the assessment of regional climate change impacts. User Manual. $67 \mathrm{pp}$.

Winkler, J. A., Palutikof, J. P., Andresen, J. A., Geodess, C. M., Wilby, R. L., Hay, L. E., Leavesley, G. H., (1999). A comparison of downscaled and raw GCM output: implications for climate change scenarios in the San Juan River basin, Colorado. Journal of Hydrology 225, 67-91. 